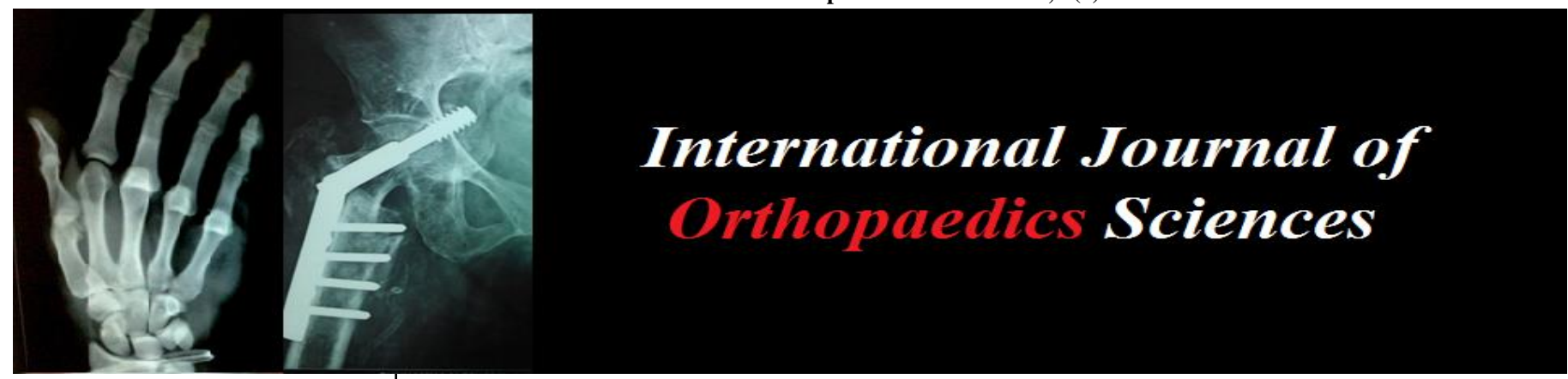

E-ISSN: 2395-1958

P-ISSN: 2706-6630

IJOS 2020; 6(1): 1305-1307

(C) 2020 IJOS

www.orthopaper.com

Received: 13-11-2019

Accepted: 15-12-2019

Dr. Tarun Kumar

Dr. Rajendra Prasad,

Government Medical College, Kangra at Tanda, Himachal

Pradesh, India

Dr. Devinder Kumar

Dr. Rajendra Prasad,

Government Medical College,

Kangra at Tanda, Himachal

Pradesh, India
Corresponding Author:

Dr. Tarun Kuma

Dr. Rajendra Prasad,

Government Medical College,

Kangra at Tanda, Himachal

Pradesh, India

\section{Effect of height on morphometric analysis of sacral vestibule S1 and S2 using plain computed tomography in North Indian population}

\author{
Dr. Tarun Kumar and Dr. Devinder Kumar
}

DOI: https://doi.org/10.22271/ortho.2020.v6.i1r.2002

\section{Abstract}

Background: The present study was aimed to study and develop in-depth understanding of the effect of height on morphometry of sacral vestibule in North-West Indian population presenting to our institution, which will go a long way in planning to treat the posterior pelvic injuries with percutaneous screws, thereby reducing the morbidity associated with open fixation.

Methods: This study was conducted in the Department of Orthopaedics and Radiodiagnosis at Dr Rajendra Prasad Govt. Medical College, Kangra at Tanda over a period of one year. All the patients of the age $>18$ years and above submitting for either abdominal, lower spinal or non-orthopaedic pathology of pelvic region, presenting for computed tomography to the Department of Radiodiagnosis were included in the study.

Results: There was a weak relation between interspinus distance with coronal angulation of $\mathrm{S} 1(\mathrm{r}=0.016$; $\mathrm{P}=0.697)$ and $\mathrm{S} 2(\mathrm{r}=0.069 ; \mathrm{P}=0.090)$. There was a weak relation between height with axial angulation of $\mathrm{S} 1$ ( $\mathrm{r}=0.037 ; \mathrm{P}=0.364)$ and $\mathrm{S} 2(\mathrm{r}=-0.034 ; \mathrm{P}=0.406)$. There was no relation between height with length of vestibule of $\mathrm{S} 1(\mathrm{r}=0.068 ; \mathrm{P}=0.093)$ and $\mathrm{S} 2(\mathrm{r}=-0.012 ; \mathrm{P}=0.766)$. There was a weak relation between height with area of vestibule of $\mathrm{S} 1(\mathrm{r}=0.062 ; \mathrm{P}=0.129)$ and $\mathrm{S} 2(\mathrm{r}=-0.035 ; \mathrm{P}=0.385)$. There a weak negative and significant relation of Alar length $(\mathrm{r}=-0.202 ; P<0.001)$, weak positive and significant relation of Alar Indentation $(\mathrm{r}=0.087 ; \mathrm{P}=0.032)$, and weak and non-significant relation of Alar width ( $\mathrm{r}=0.072 ; \mathrm{P}=0.077)$ with height.

Conclusion: The present study, the first of its kind in Northern part of India arrived to help us anthropometric measurements of sacral vestibule, thereby, helping in development of local protocols for percutaneous fixation in sacral fracture.

Keywords: Sacral, coronal angulation, axial angulation, alar length, alar indentation, alar width

\section{Introduction}

The sacral bone is an inverted triangle that sits obliquely between the two innominate bones of the pelvis at the distal aspect of the spinal column. It functions mechanically to convey axial load from the lumbar spine into the lower extremities for balanced locomotion. The ventral sacral body is concave and derived from five vertebrae. The transverse processes of the sacral vertebrae coalesce to form the sacral ala, which projects laterally from the upper sacral promontory ${ }^{[1]}$.

The standard treatment of unstable sacral fractures is surgical fixation due to a high incidence of residual morbidity under conservative treatment. The primary goal is anatomic reduction, followed by a rigid fracture fixation. There are several operating techniques like fixation with iliosacral screws or plates, triangular osteosynthesis, ilioiliac (plates, internal fixators, and bars) and trans-sacral screws or bars. In recent years, sacroiliac screws and spinopelvic internal fixators have become the preferred implants for fixation of posterior pelvic ring fractures. Whereas full weight bearing is allowed for most spinopelvic fixations, none or partial weight bearing is recommended for iliosacral screw fixations ${ }^{[2]}$.

The present study was aimed to study and develop in-depth understanding of the morphometry of sacral vestibule in North-West Indian population presenting to our institution, which will go a long way in planning to treat the posterior pelvic injuries with percutaneous screws, thereby reducing the morbidity associated with open fixation. 


\section{Materials and Methods}

This study was conducted in the Department of Orthopaedics and Radiodiagnosis at Dr Rajendra Prasad Govt. Medical College, Kangra at Tanda over a period of one year. All the patients of the age $>18$ years and above submitting for either abdominal, lower spinal or non-orthopaedic pathology of pelvic region, presenting for computed tomography to the Department of Radiodiagnosis were included in the study. The patients were informed about the aims and methods of the study and once consent was given for participation; they were evaluated. The evaluation included clinical assessment for height. This helped to draw comparison while arriving at morphometry of Sacral vestibule.

The following patients were excluded from the study

1. Age $<18$ years.

2. The patient with pelvic ring dysmorphism.

3. Osteolytic pelvic lesions.

4. Fractures involving the posterior elements.

5. Post operated cases of above fracture

6. Not willing to participate in the study

7. Implants obscuring the lumbosacral junction.

Each patient and his attendants ware adequately informed about the aims, methods, the anticipated benefits and potential risks of the study and the discomfort it might entail them and the remedies thereof. Every precaution was taken to respect the privacy of the patient, the confidentiality of the patient's information and to minimize the impact of the study on his/her physical and mental integrity and personality. The patients were given the right to abstain from participation in the study or to withdraw consent to participate at any time of the study without reprisal. Due care and caution were taken at all stages of the research to ensure that the patient was put to minimum risk, suffer from no irreversible adverse effects and generally, benefit from and by the research. Written informed consent was obtained from all the patients and attendants included in the study.

The subjects included in this study followed the protocol generally used by the Department of Radiodiagnosis for the conditions mentioned above. The subjects were placed in the supine position with fully extended knee joint with patella facing the sky for $\mathrm{CT}$ examination. 3D volume reconstruction of surface anatomy of bony pelvis was then performed using available CT data.

All CT scan were included scanning by anteroposterior tomogram as well as axial images of Sacral Vestibule. All angles were measured at the CT work station. Measurements of the angles were performed by a junior resident (the investigator) from the Department of Orthopaedics Dr. RPGMC Tanda and were supervised by consulting Orthopaedician and Radiologist.

Following parameters were noted in each patient according to the sex of the patient:
A. Coronal angulations
B. Axial angulations
C. Minimum Area of the vestibule
D. Maximum Length of vestibule
E. Width of vestibule
F. Alar indentation
G. Alar length

\section{Statistical Analyses}

Data were presented as frequency, percentages, and median (inter quartile range; IQR). Difference between quantitative variables was compared using Mann Whitney U test. Spearman correlation coefficient was used to find relation between two variables. $\mathrm{P}$ value $<0.05$ was considered significant. Statistical analyses were performed using SPSS v20.

\section{Height}

The maximum number of patients' ( $\mathrm{n}=317 / 610 ; 52 \%)$ height were ranged from 151-160 $\mathrm{cm}$ while minimum number of patients' $(\mathrm{n}=61 / 610 ; 10 \%)$ height ranged in $171-180 \mathrm{~cm}$. Height of the patients' ranged from 150 to $177 \mathrm{~cm}$ with a mean height of $161.07 \mathrm{~cm}$.

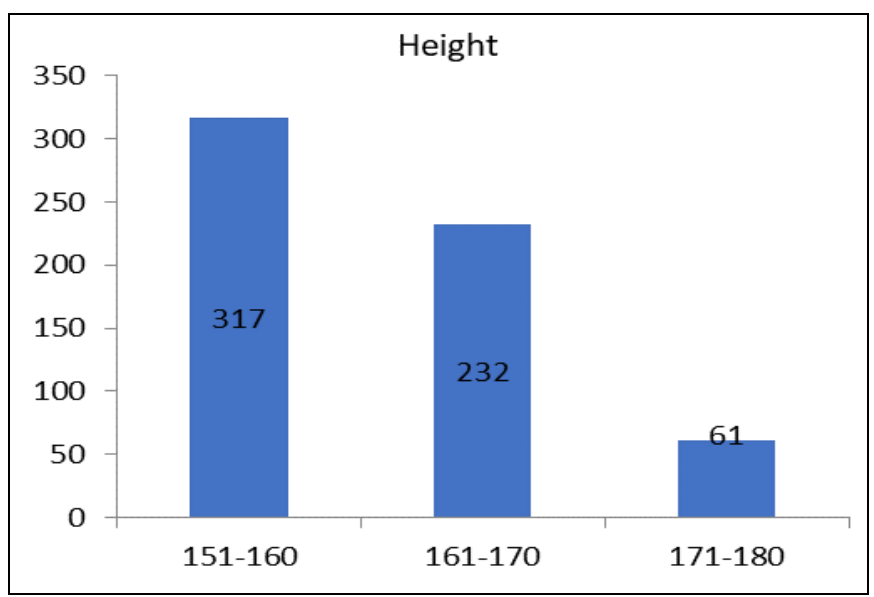

Fig 1: Distribution of patients on the basis of height $(\mathrm{n}=610)$.

\section{Morphological Analysis of Sacral Vestibule Coronal Angulation}

Table shows coronal angulation of S1 and S2.

\begin{tabular}{|c|c|c|}
\hline & S1 & S2 \\
\hline Minimum & $11^{\circ}$ & $1^{\circ}$ \\
\hline Maximum & $33^{\circ}$ & $10^{\circ}$ \\
\hline Mean & $22.04^{\circ} \pm 6.59^{\circ}$ & $5.06^{\circ} \pm 2.77^{\circ}$ \\
\hline Median & 22 & 5 \\
\hline IQR & 16 & 3 \\
\hline
\end{tabular}

Relation with Height

\begin{tabular}{|c|c|c|}
\hline & Correlation Coefficient (r) & P Value \\
\hline S1 & 0.000 & 0.999 \\
\hline S2 & 0.019 & 0.631 \\
\hline
\end{tabular}

There was no relation between height with coronal angulation of $\mathrm{S} 1$ $(\mathrm{r}=0.000 ; \mathrm{P}=0.999)$ and $\mathrm{S} 2(\mathrm{r}=0.019 ; \mathrm{P}=0.631)$.

\section{Axial Angulation}

Table shows descriptive analysis of axial angulation of S1 and S2.

\begin{tabular}{|c|c|c|}
\hline & S1 & S2 \\
\hline Minimum & $2^{\circ}$ & $-1^{\circ}$ \\
\hline Maximum & $23^{\circ}$ & $8^{\circ}$ \\
\hline Mean & $11.01^{\circ} \pm 3.74^{\circ}$ & $3.51^{\circ} \pm 2.88^{\circ}$ \\
\hline Median & 10 & 3 \\
\hline IQR & 10 & 3 \\
\hline
\end{tabular}

Relation with Height

\begin{tabular}{|c|c|c|}
\hline & Correlation Coefficient (r) & P Value \\
\hline S1 & 0.037 & 0.364 \\
\hline S2 & -0.034 & 0.406 \\
\hline
\end{tabular}

There was a weak relation between height with axial angulation of $\mathrm{S} 1(\mathrm{r}=0.037 ; \mathrm{P}=0.364)$ and $\mathrm{S} 2(\mathrm{r}=-0.034 ; \mathrm{P}=0.406)$. 


\section{Length of Vestibule S1 and S2}

Table shows descriptive analysis of length of vestibule of S1 and S2.

\begin{tabular}{|c|c|c|}
\hline & S1 & S2 \\
\hline Minimum & 98.60 & 108.20 \\
\hline Maximum & 128.2 & 128.60 \\
\hline Mean & $112.08 \pm 6.21$ & $128.60 \pm 11.85$ \\
\hline Median & 111.5 & 128 \\
\hline IQR & 111.5 & 128 \\
\hline
\end{tabular}

Relation with Height

\begin{tabular}{|c|c|c|}
\hline & Correlation Coefficient (r) & P Value \\
\hline S1 & 0.068 & 0.093 \\
\hline S2 & -0.012 & 0.766 \\
\hline
\end{tabular}

There was no relation between height with length of vestibule of $\mathrm{S}$ $(\mathrm{r}=0.068 ; \mathrm{P}=0.093)$ and $\mathrm{S} 2(\mathrm{r}=-0.012 ; \mathrm{P}=0.766)$.

\section{Area of Vestibule}

Table shows descriptive analysis of vestibule area of S1 and S2.

\begin{tabular}{|c|c|c|}
\hline & S1 & S2 \\
\hline Minimum & 330.0 & 162.0 \\
\hline Maximum & 460.0 & 283.0 \\
\hline Mean & $396.03 \pm 37.13$ & $224.74 \pm 36.14$ \\
\hline Median & 397 & 226 \\
\hline IQR & 397 & 226 \\
\hline
\end{tabular}

Relation with Height

\begin{tabular}{|c|c|c|}
\hline & Correlation Coefficient (r) & P Value \\
\hline S1 & 0.062 & 0.129 \\
\hline S2 & 0.035 & 0.385 \\
\hline
\end{tabular}

There was a weak relation between height with area of vestibule of $\mathrm{S} 1(\mathrm{r}=0.062 ; \mathrm{P}=0.129)$ and $\mathrm{S} 2(\mathrm{r}=-0.035 ; \mathrm{P}=0.385)$.

Alar Length, Indentation, and Width (mm)

\begin{tabular}{|c|c|c|c|}
\hline & Alar Length & Alar Indentation & Alar width \\
\hline Minimum & 31.0 & 4.0 & 25.0 \\
\hline Maximum & 39.0 & 6.0 & 36.0 \\
\hline Mean & $35.60 \pm 2.37$ & $4.99 \pm 0.80$ & $30.39 \pm 3.41$ \\
\hline Median & 36 & 5 & 30 \\
\hline IQR & 36 & 5 & 30 \\
\hline
\end{tabular}

Table shows descriptive analysis of alar length, alar indentation, and alar width.

Relation with Height

\begin{tabular}{|c|c|c|}
\hline & Correlation Coefficient (r) & P Value \\
\hline Alar Length & -0.202 & $<0.0001$ \\
\hline Alar Indentation & 0.087 & 0.032 \\
\hline Alar Width & 0.072 & 0.077 \\
\hline
\end{tabular}

There was a weak negative and significant relation of Alar length $(\mathrm{r}=-0.202 ; P<0.001)$, weak positive and significant relation of Alar Indentation ( $\mathrm{r}=0.087 ; \mathrm{P}=0.032)$, and weak and non-significant relation of Alar width $(\mathrm{r}=0.072 ; \mathrm{P}=0.077)$ with height.

\section{Discussion}

The sacral vestibule refers to the three-dimensional (3D) screw space that is available in the narrowest part of the iliosacral screw channel. The sacral vestibule is located in the transition zone between the sacral wing and sacral body and serves as the entrance to the sacral vertebrae. The vestibule is divided into two components, the $\mathrm{S} 1$ and $\mathrm{S} 2$ vestibules. The smaller S2 vestibule is associated with limited tolerance for screw misdirection, which can increase the risk of nerve injury or spinal canal damage. Therefore, S2 vestibules are rarely used for screw replacement. The S1 vestibule, located above the sacral foramina and between the sacral foramina and the slope of the sacral wing, is the isthmus of the transition zone between the sacral wing and the S1 vertebrae. The present study was aimed to morphometrically analyze sacral vestibule using CT at Department of Orthopaedics, Dr RPGMC Kangra at Tanda. A total of 610 patients were included in the study.

We also found that area of $\mathrm{S} 1$ and $\mathrm{S} 2$ vestibules were nonsignificantly higher in males in comparison to female counterparts. The similar findings have previously been reported by Dong et al. ${ }^{[3]}$. Dong et al. showed that vestibule width and height were significantly higher in males when compared with females. The proper location to insert iliosacral screws is parallel to the long diameter with the inclination angle of the vestibule; therefore, these both parameters are very important references for the operation. Due to smaller size in these parameters, the insertion location, direction of the screw, and the position relationships between the screws are particularly limited for female patients ${ }^{[4]}$. Sacral variations are common in Indian population; however, these parameters are higher than Chinese populations ${ }^{[5]}$.

Therefore, the placement of iliosacral screws should be considered carefully based on the size, gender, height and ethnicity of the patient

The present study was aimed to study the effect of height on morphometric analysis of sacral vestibule using plain computed tomography. A total of 610 patients were included in the study.

Maximum number of patients' ( $n=317 / 610 ; 52 \%)$ height were ranged from 151-160 cm while minimum number of patients' $(\mathrm{n}=61 / 610 ; 10 \%)$ height. ranged in $171-180 \mathrm{~cm}$.

There was no relation between height with coronal angulation of $\mathrm{S} 1(\mathrm{r}=0.000 ; \mathrm{P}=0.999)$ and $\mathrm{S} 2(\mathrm{r}=0.019 ; \mathrm{P}=0.631)$. There was a weak relation between height with axial angulation of $\mathrm{S} 1(\mathrm{r}=0.037 ; \mathrm{P}=0.364)$ and $\mathrm{S} 2(\mathrm{r}=-0.034 ; \mathrm{P}=0.406)$. There was no relation between height with length of vestibule of $\mathrm{S} 1$ $(\mathrm{r}=0.068$;

$\mathrm{P}=0.093)$ and $\mathrm{S} 2(\mathrm{r}=-0.012 ; \mathrm{P}=0.766)$. A weak negative and significant relation of Alar length $(\mathrm{r}=-0.202 ; P<0.001)$, weak positive and significant relation of Alar Indentation ( $\mathrm{r}=0.087$; $\mathrm{P}=0.032$ ), and weak and non-significant relation of Alar width $(\mathrm{r}=0.072 ; \mathrm{P}=0.077)$ with height was observed.

\section{Conclusion}

The present study, the first of its kind in Northern part of India arrived to help us anthropometric measurements of sacral vestibule, thereby, helping in development of local protocols for percutaneous fixation in sacral fracture.

\section{References}

1. Sugar O. How the Sacrum Got Its Name. JAMA. 1987; 257:2061-3.

2. Mehta S, Auerbach JD, Born CT, Chin KR. Sacral fractures. J Amer Acad Orthop Surg. 2006; 14(12):65665.

3. Dong Q, Tian W, Ma B. Evaluation and clinical application of sacral $\mathrm{S} 1$ vestibule measurements in Chinese adults. Int. J. Morphol. 2014; 32(1):202-7.

4. Singh ID, Ajita R, Singh N. Variation in the number of sacral pieces. IOSR Journal of Dental and Medical Sciences (IOSR-JDMS). 2015; 14:106-8.

5. Kaiser SP, Gardner MJ, Liu J, Routt ML Jr, Morshed S. Anatomic determinants of sacral dysmorphism and implications for safe iliosacral screw placement. J Bone Joint Surg Am. 2014; 96(e120):1-8. 